\title{
A multivariate analysis of the factors that influence the modification of sexual desire in oral hormonal contraceptive (OC) users
}

\author{
Mariano Martin-Loeches ${ }^{1 *}$, Yadira Pallas ${ }^{1}$, Pedro Lopez Sanchez ${ }^{2}$, Manuel Lloret ${ }^{1}$, \\ Jose Jesús Lopez-Galvez ${ }^{1}$
}

${ }^{1}$ Department of Human Reproduction, “San Carlos” General Hospital, Denia (Alicante), Spain;

${ }^{2}$ Department of Gynaecologia, “Marina Alta” University Hospital, Denia (Alicante), Spain.

E-mail: mm-loeches@coma.es

Received 4 July 2011; revised 12 August 2011; accepted 19 August 2011.

\section{ABSTRACT}

Objectiv: This work studied the influencing factors of age, level of education, family planning awareness, relationship with partner, the age at which sexual relationships were initiated, parity, the method of contraceptive previously used, the type of contraceptive pill used and the duration of oral hormonal contraception (OC) use in relation to the modification of sexual desire in OC users. Materials and Methods. Prospective study of 760 OC users at the Family Planning Center “Marina Alta” in Alicante (Spain). A logistical regression analysis was carried out to study the relative risk of reduction in libido, taking other risk factors into account. Results: In the simple analysis, women who initiated sexual relationships between 18 and 25 years of age had a lower sexual desire in comparison with women who were sexually active before the age of $18(\mathrm{OR}=2.11$; CI: 1.15 - 3.91). Nulliparous women had a reduced sexual desire compared with those women that had given birth $(\mathrm{OR}=$ 2.32; CI: 1.41 - 3.82). An OC use of between 6 months and 1 year reduced sexual desire in comparison with a use of less than 6 months $(\mathrm{OR}=0.24$; CI: 0.09 $0.64)$. In the multivariate analysis, age $(\mathrm{OR}=1.12$; $\mathrm{CI}$ : 1.01 - 1.21) and the use of OC within an initial 6 month to a year period $(\mathrm{OR}=0.24$; CI: $0.09-0.64)$ presented a statistically significant relationship with the modification of sexual desire. The level of education, family planning awareness, relationship with partner, the method of contraception previously used and the type of contraceptive pill prescribed showed no statistical significance with the modification of sexual desire in OC users. Conclusions: Sexual desire in OC users decreases as a woman's age increases and in an early stage of use in the first six months after beginning OC treatment.

Keywords: Oral Contraceptive; Sexual Desire; Sex Hormones

\section{INTRODUCTION}

The human sexual response or libido is a complex phenomenon which combines biological factors, via hormonal stimuli, and psychosocial factors in the form of internal and external stimuli regulated by the central nervous system, resulting in a cascade of biochemical, hormonal and circulatory changes [1-4]. It is characterised by a desire to maintain or initiate sexual relationships and varies between human beings as it is subject to large fluctuations [4]. Its neuroanatomical and neurophysiological bases have yet to be accurately established $[5,6]$ and to date no substance has been isolated with which a biological theory on the subject might be developed [7].

Contraception should not only be directed at avoiding unwanted pregnancy, yet al.so at favouring the development of the sexual facet of the human being, in whom it plays an integral and undeniably important role. The above factors are, therefore, two activities which are intrinsically linked and which the prescribing doctor should always take into account $[7,8]$.

Studies of the evolution of sexual desire during the physiological menstrual cycle demonstrate an increase in this desire halfway through the cycle, coinciding with ovulation, and a decrease in the early luteal phase and a further increase in the late luteal phase [9]. The action mechanism of hormones is not totally clear [9,10] and although estroprogestatives are one of the influencing factors in sexual behaviour (decrease in interest, desire, etc), they are by no means the most important factor [10].

Likewise, some studies affirm the influence of age on sexual activity, demonstrating that female adolescents 
present an increase in coital relationships compared with older women [11,12].

The aim of this work is to study the influencing factors of age, level of education, family planning awareness, relationship with partner, the age at which sexual relationships were initiated, parity, the method of contraceptive previously used, the type of contraceptive pill used and the duration of OC use in relation to the modification of sexual desire in OC users.

\section{MATERIAL AND METHODS}

Prospective study of 760 OC users, with no signs or suspicion of organic or psychological illness was carried out between January of 2000 to January of 2010 at the Family Planning Center "Marina Alta” in Alicante (Spain).

The general characteristics of these women were studied regarding to the age, level of education, family planning awareness, relationship with partner, age at which the sexual relationships were initiated, parity, the method of contraceptive previously used, the type of contraceptive pill prescribed, the duration of OC treatment and the modification of sexual desire. The established medical controls were carried out at 3, 6 and 12 months after commencing treatment.

The mean age of the women in this study was of 26.6 \pm 4.1 years of age (with a range which oscillated between 15 and 34 years). 518 women (68.1\%) had elementary education (basic education) and 231 women (30.4\%) had an intermediate or higher level of university degrees. 87 women (11.4\%) possessed no information on family planning (they are aware of various methods but practise coitus interruptus and use condoms with some reservation), 287 women (53\%) had a basic awareness ( they use condoms and know of the contraceptive pill and IUD) and 430 women $(34.7 \%)$ were well informed (they know of almost all existing methods and have read literature on the subject). With regard to partner relationship, 644 women (84.8\%) enjoyed a good relationship, 85 women (11.21\%) qualified their relationship as average, and 15 (1.9\%) as poor. 250 women (32.9\%) initiated sexual relationships before 18 years of age, 85 women (62.2\%) did so between 18 and 25 years of age whilst 15 women (2.4\%) initiated sexual activity after the age of 25.485 women (63.8\%) were nulliparous whilst 274 (36.1\%) were multiparous. 158 women (26.6\%) used a preparation containing 30 micrograms of ethinylestradiol and 150 micrograms of desogestrel (Microdiol ${ }^{\circledR}$ ), 202 women (20.8\%) used 35 micrograms of ethinylestradiol and 2 milligrams cyproterone acetate (Diane ${ }^{\circledR}$ ), 360 women (47.3\%) were prescribed ethinylestradiol and triphasic levonorgestrel (Triagynon ${ }^{\circledR}$ and Triciclor $^{\circledR}$ ) and 40 women $(5.3 \%)$ received 30 micrograms of ethinylestradiol and 75 micrograms of gestodene (Gynovin ${ }^{\circledR}$ and Minu- let $\left.{ }^{\circledR}\right)$. 37 women (4.9\%) used the product for less than 3 months, 287 women (37.8\%) for less than a year and 430 women (56.5\%) used the product for over a year.

With regard to a modification of sexual desire, the Female Sexual Function Index (FSFI) was used [13,14], which consisted of a questionnaire made available by the sexologist, in which each woman rated six main characteristics-sexual desire, subjective arousal, vaginal lubrication, orgasm, satisfaction and discomfort during coitus. A decrease in sexual desire was classified as slight, moderate and significant

In order to analyse the relative risk of the different OC on sexual desire independently of the presence of other risk factors, a logistical regression analysis was carried out, which adjusted the effect of the variables, preventing the presence of after effects and including the variables which could act as potential confusers. The data base and the computer processed analysis were carried out using the data analysis program "SSPS" (Statistical Package for Social Sciences) 6.1 version for Windows (licence $\mathrm{N}^{\circ}$ 707852).

\section{RESULTS}

The findings of the study revealed that 42 women (5.4\%) experienced an increase in sexual desire, 182 women (23.6\%) experienced a decrease and 536 women (70.3\%) registered no modification of their sexual desire.

In the simple analysis, those women who initiated sexual relationships between 18 and 25 years of age registered a lesser sexual desire than those who became sexually active before the age of 18 (OR $=2.11$; CI: 1.15 3.91). Nulliparous women showed a decrease in sexual desire in relation to women that had given birth $(\mathrm{OR}=$ 2.32; CI: 1.41 - 3.82). The use of OC within an initial 6 to 12 month period increased sexual desire compared to a use of less than 6 months (OR $=0.21$; CI: $0.08-0.60)$ (Table 1).

The multivariate analysis revealed a statistically significant relationship between the modification of sexual desire and age (OR = 1.12; CI: $1.03-1.21$ ) and the use of OC for 6 months to a year (OR = 0.24; CI: 0.09 - 0.64). The level of education, level of family planning awareness, partner relationship, the contraceptive method previously used and the type of contraceptive pill prescribed showed no statistical significance with the modification of sexual desire in OC users (Table 2 and Figure 1).

\section{DISCUSION}

Studies of the evolution of sexual desire during the physiological menstrual cycle demonstrate an increase in this desire halfway through the cycle, coinciding with ovulation, and a decrease in the early luteal phase and a further increase in the late luteal phase [15], with a higher levels 
Table 1. Simple analysis of the modification of sexual desire in female oral hormonal contraceptive (OC) users.

\begin{tabular}{|c|c|c|c|c|}
\hline & & $\mathbf{p}$ & Odds Ratio & CI 95\% OR \\
\hline \multirow[t]{2}{*}{ Level of studies } & Elementary & & 1 & 1 \\
\hline & Intermediate/high & 0.92 & 0.98 & $(0.57-1.66)$ \\
\hline \multirow[t]{3}{*}{ Family planning information } & Nil & & 1 & 1 \\
\hline & Basic & 0.53 & 1.29 & $(0.56-3.1)$ \\
\hline & Good & 0.98 & 1 & $(0.4-2.5)$ \\
\hline \multirow[t]{3}{*}{ Partner relationship } & Good & & 1 & 1 \\
\hline & Average & 0.36 & 1.37 & $(0.65-2.83)$ \\
\hline & Poor & 0.2 & 2.3 & $(0.5-9.1)$ \\
\hline \multirow[t]{3}{*}{ Age SR initiated } & $<18$ years & & 1 & 1 \\
\hline & 18 to 25 years & 0.01 & 2.11 & $(1.15-3.91)$ \\
\hline & $>25$ years & 0.4 & 1.83 & $(0.27-9.47)$ \\
\hline \multirow[t]{2}{*}{ Parity } & Yes & & 1 & 1 \\
\hline & No & $<0.001$ & 2.32 & $(1.41-3.82)$ \\
\hline \multirow[t]{4}{*}{ Type of OC } & 30 mcg EE + 150 mcg DG & & 1 & 1 \\
\hline & 35 mcg EE + 2 mg AC & 0.93 & 1.03 & $(0.49-2.16)$ \\
\hline & $\mathrm{EE}+$ triphasic LN & 0.67 & 1.14 & $(0.6-2.2)$ \\
\hline & 30 mcg EE + 75 mcg G & 0.12 & 0.23 & $(0.01-1.72)$ \\
\hline \multirow[t]{3}{*}{ Duration of use } & $<6$ months & & 1 & 1 \\
\hline & 6 to 12 months & $<0.001$ & 0.21 & $(0.08-0.6)$ \\
\hline & $>12$ months & 0.13 & 0.53 & $(0.22-1.34)$ \\
\hline
\end{tabular}

$\mathrm{CI}=$ Confidence interval; $\mathrm{OR}=$ Odds ratio; FP = Family planning; $\mathrm{SR}=$ Sexual relationships; $\mathrm{EE}=$ Ethinylestradiol; $\mathrm{DG}=$ Desogestrel; $\mathrm{CA}=\mathrm{Cyproterone}$ acetate; $\mathrm{LN}=$ Levonorgestrel; $\mathrm{G}=$ Gestodene.

Table 2. Logistical regression analysis of the modification of sexual desire in female oral hormonal contraceptive (OC) users.

\begin{tabular}{|c|c|c|c|c|}
\hline & & $\mathrm{p}$ & Odds Ratio & CI 95\% OR \\
\hline Age (years) & & 0.005 & 1.12 & $(1.03-1.2)$ \\
\hline \multirow[t]{2}{*}{ Level of studies } & Elementary & & 1 & 1 \\
\hline & Intermediate/higher & 0.35 & 1.32 & $(0.73-2.38)$ \\
\hline \multirow[t]{3}{*}{ PF information } & Nil & & 1 & 1 \\
\hline & Basic & 0.77 & 1.14 & $(0.48-2.7)$ \\
\hline & Good & 0.78 & 0.88 & $(0.34-2.25)$ \\
\hline \multirow[t]{3}{*}{ Partner relationship } & Good & & 1 & 1 \\
\hline & Average & 0.56 & 1.23 & $(0.6-2.51)$ \\
\hline & Poor & 0.51 & 1.62 & $(0.38-6.86)$ \\
\hline \multirow[t]{3}{*}{ Age SR initiated } & $<18$ years & & 1 & 1 \\
\hline & 18 to 25 years & 0.29 & 1.42 & $(0.74-2.7)$ \\
\hline & $>25$ years & 0.83 & 1.2 & $(0.22-6.41)$ \\
\hline \multirow[t]{2}{*}{ Parity } & Yes & & 1 & 1 \\
\hline & No & 0.1 & 1.6 & $(0.92-2.79)$ \\
\hline \multirow[t]{4}{*}{ Type of OC } & $30 \mathrm{mcg}$ EE $+150 \mathrm{mcg}$ DG & & 1 & 1 \\
\hline & 35 mcg EE + 2 mg AC & 0.78 & 0.9 & $(0.43-1.9)$ \\
\hline & $\mathrm{EE}+$ triphasic LN & 0.76 & 1.1 & $(0.57-2.13)$ \\
\hline & $30 \mathrm{mcg}$ EE + 75 mcg G & 0.2 & 0.24 & $(0.27-2.11)$ \\
\hline \multirow[t]{3}{*}{ Duration of use } & $<6$ months & & 1 & 1 \\
\hline & 6 to 12 months & 0.04 & 0.24 & $(0.09-0.64)$ \\
\hline & > 12 months & 0.11 & 0.48 & $(0.2-1.2)$ \\
\hline
\end{tabular}

$\overline{\mathrm{CI}}=$ Confidence interval; OR = Odds ratio; FP = Family planning; SR = Sexual relationships; EE = Ethinylestradiol; DG = Desogestrel; CA = Cyproterone acetate; LN = Levonorgestrel; G = Gestodene. 


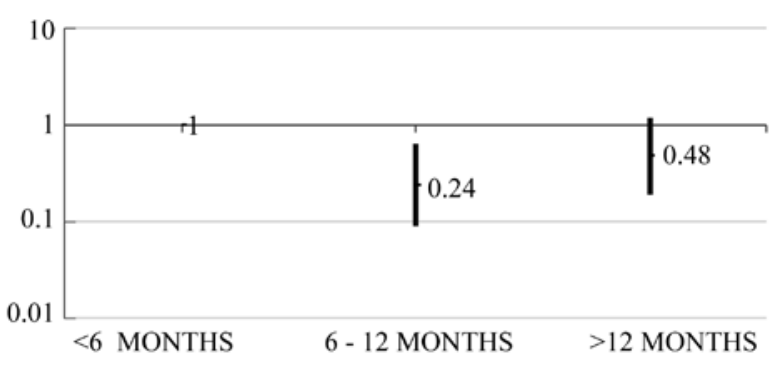

Figure 1. Relative risk of the decrease in sexual desire in relation to the duration of oral hormonal contraceptive (OC) use.

of androgens obtained in these phases accounting for the increase in sexual desire [16]. However, a decrease in sexual desire is produced in OC users during the menstrual and postmenstrual phases [13,17], due to the decrease in the free testosterone plasma levels and other androgens [3].

The action mechanism of hormones with regard to the human sexual response is not totally clear $[9,10]$. Gladkova [18], Bancroft [3] and other authors [11,19] refer to the relationship between sexual desire and androgens, in that women with a higher level of free testosterone plasma levels present an increased rate of coitus and an increase in sexual arousal and the human sexual response to stimuli [1,20]. Hutchison [20] and van Lunsen and Laan [1] state that the increase in the binding globulin of sexual hormones produces similar responses. Warnock et al. [21] and other authors [9,22] refer to the fact that changes in sexuality are due to gestagens and the antiandrogenic effect of estroprogestatives, with estrogens playing a lesser role in the modification of sexual desire in women, although van Goozen et al. [15] do not agree with this proposal.

Estroprogestatives are also an influencing factor in sexual behaviour (decrease in interest, desire etc), but are by no means the most important [10]. To this effect Bancroft affirms that psychosocial influences have a greater influence than the reduction of androgens caused by OC treatment with regard to the decrease in sexual desire [3] and that users have a higher rate of sexual activity, greater motivation with regard to sex and are far more positive in evaluating their partner relationship [2]. Sa- batini and Cagiano [23] states that OC users that have made an informed choice are aware of the benefits and risks and understand the efficiency of the method, pre- sent a better acceptance of this contraceptive method. However, Bastianelli et al. [24], in accordance with this study, affirm finding a decrease in sexual desire within the first semester of OC treatment.

Literature on the subject matter calculates the decrease in sexual desire to be at between $5 \%$ and $6 \%$ of women in studies carried out by Renier [25] and up to $31 \%$ in stu- dies by Gómez [26] and Graham et al. [22]. Findings in this study calculate the reduction in sexual desire in women to be at $24 \%$, in agreement with Bastianelli [24]. Other authors, such as Caruso et al. [27], place this decrease at $10 \%$ of users, whilst authors such as Oddens [28] calculate the decrease to be at $16 \%$.

The use of OC is influenced by a great number of emotional factors, such as the distinction between sexuality and fertility $[20,24]$, which consequently give rise to psychological conflicts regarding pregnancy within a relationship, although Spanish users give the contraceptive pill a positive valuation [23]. Byne et al. [29] state that temperament and character within the social and family environment of a person is more important than hormonal influence in sexual desire. Lachowsky [30] affirms that the use of OC methods has modified traditional behavioural models, personal relationships between the sexes and has brought love and sexuality closer together, whilst Bancroft et al. [2] suggest that their use has given rise to a diminishing of restrictive sexual morality.

McCoy et al. [31] publish that monophasic preparations give rise to a reduction in vaginal lubrication when compared with the results of triphasic treatments, thus producing an increase in sexual desire in triphasic OC users, our study, however, does not coincide with these results.

Creatsas et al. [11], coinciding with the findings presented in this study, describe an increase in the rate of coital activity in adolescents compared to this activity in older women, thus demonstrating a statistically significant relationship between sexual activity and age.

\section{CONCLUSIONS}

Sexual desire in female OC users decreases as the age of women increases and increases within the first semester to 12 months of OC treatment.

\section{REFERENCES}

[1] Van, L.R.H. and Laan, E. (1997) Sex, hormones and brain. The European Journal of Contraception and Reproductive Health Care, 2, 247-251. doi:10.3109/13625189709165302

[2] Bancroft, J. (1991) Oral, contraceptives, androgens and the sexuality of young women: I. A comparison of sexual experience, sexual attitudes and gender role in oral contraceptive users and nonusers. Archives of Sexual Behavior, 20, 105-120. doi:10.1007/BF01541938

[3] Bancroft, J. (1991) Oral contraceptives, androgens and the sexuality of young women: II. the role of androgens. Archives of Sexual Behavior, 20, 121-135. doi:10.1007/BF01541939

[4] Davis, A.R. and Castaño, P.M. (2004) Oral contraceptives and libido in women. Annual Review of Sex Research, 15, 297-320. 
[5] Bamji, M.S. (1985) Vitamin supplements to Indian women using low dosege oral contraceptives. Contraception, 32, 405-416. doi:10.1016/0010-7824(85)90044-7

[6] Greco, T., Graham, C.A., Bancroft, J., Tanner, A. and Doll, H.A. (2007) The effects of oral contraceptives on androgen levels and their relevance to premenstrual mood and sexual interest: A comparison of two triphasic formulations containing norgestimate and either 35 or 25 microg of ethinyl estradiol. Contraception, 76, 8-17. doi:10.1016/j.contraception.2007.04.002

[7] Stuckey, B.G. (2008) Female sexual function and dysfunction in the reproductive years: The influence of endogenous and exogenous sex hormones. Journal of Sexual Medicine, 5, 2282-2290. doi:10.1111/j.1743-6109.2008.00992.x

[8] Strufaldi, R., Pompei, L.M., Steiner, M.L., Cunha, E.P., Ferreira, J.A. et al. (2010) Effects of two combined hormonal contra-ceptives with the same composition and different doses on female sexual function and plasma androgen. Contraception, 82, 147-154. doi:10.1016/j.contraception.2010.02.016

[9] Meuwissen, I. and Over, R., (1992) Sexual arousal across phases of the human menstrual cycle. Archives of Sexual Behavior, 21, 101-119. doi:10.1007/BF01542588

[10] Warner, P. and Bancroft, J. (1988) Mood, sexuality, oralcontraceptives and the menstrual cycle. Journal of Psychosom Research, 32, 417-427. doi:10.1016/0022-3999(88)90025-6

[11] Creatsas, G.K. (1993) Sexuality: Sexual activity and contraception during adolescence. Current Opinion Obstetrics and Gynecology, 5, 774-783.

[12] Wallwiener, C.W., Wallwiener, L.M., Seeger, H., Muco, A.O., Bitzer, J. and Wallwiener, M. (2010) Prevalence of sexual dysfunction and impact of contraception in female German medical students. Journal of Sexual Med-icine, 7, 2139-2148.

[13] Taylor, J.F., Rosen, R.C. and Leiblum, S.R. (1994) Selfreport assessment of female sexual function: Psychometric evaluation of the brief index of sexual functioning for women. Archives of Sexual Behavior, 23, 627643. doi:10.1007/BF01541816

[14] Rosen, R., Brown, C., Heiman, J. et al. (2000) The Female Sexual Function Index (FSFI): A multidimensional self-report instrument for the assessment of female sexual function. Journal of Sex Marital Therapy, 26, 191-208. doi:10.1080/009262300278597

[15] Van G.S.H., Wiegant, V.M., Endert, E., Helmond, F.A. and Van, D.P.N.E. (1997) Psychoendocrinological assement of the menstrual cycle: The relationship between hormones, sexuality and mood. Archives of Sexual Behavior, 26, 359-382. doi:10.1023/A:1024587217927

[16] Lindman, R.E., Koskelainen, B.M. and Eriksson, C.J. (1999) Drinking, menstrual circle and female sexuality: A diary study. Alcohology Clinical Experiment Research, 23, 169-173.

[17] Graham, C.A. (1993) The relationship between mood and sexuality in women using an oral contraceptive as a treatment for premenstrual symptoms. Phychoneuro, 4,

\section{3-281. doi:10.1016/0306-4530(93)90024-F}

[18] Gladkova, A.I. (1999) The regulation of male sexual behavior by the sex hormones. Usp Fiziol Nauk, 30, 97105.

[19] Alexander, G.M. (1993) Sex steroids, sexual behavior and selection attention for erotic stimuli in women using oral contraceptives. Psychoneuro, 18, 91-102. doi:10.1016/0306-4530(93)90060-X

[20] Hutchinson, K.A. (1995) Androgens and sexuality. American Journal of Medicine, 98, 111-115. doi:10.1016/S0002-9343(99)80068-0

[21] Warnock, J.K., Clayton, A., Croft, H., Segraves, R. and Biggs, F.C. (2006) Comparison of androgens in women with hypoactive sexual desire disorder: Those on combined oral contraceptives (COCs) versus those not on COCs. Journal of Sexual Medicine, 3, 8788-8882. doi:10.1111/j.1743-6109.2006.00294.x

[22] Graham, C.A., Ramos, R., Bancroft, J., Maglaya, C. and Farley, T.M. (1995) The effects of steroidal contraceptives on the well-being and sexuality of women: A double-blind, placebo-controlled, two-centre study of combined and proge-stogen-only methods. Contraception, 52, 363-369. doi:10.1016/0010-7824(95)00226-X

[23] Sabatini, R. and Casiano, R. (2006) Comparison profiles of cycle control, side effects and sexual satisfaction of three hormonal contraceptives. Contraception, 74, 220223. doi:10.1016/j.contraception.2006.03.022

[24] Bastianelli, C. (1993) Estroprogesticini e desiderio sessuale. Giorn It Ost Gin, 9, 655-657.

[25] Renier, M. (1991) Poen prospective multicentric trial with a new monophasic contraceptive combination containing gestoden. Contraception, 43, 413-421. doi:10.1016/0010-7824(91)90132-Y

[26] Gomez, M.A. (1997) Satisfacción y aceptabilidad de la anticon-cepción hormonal oral y del dispositivo intrauterino. Clin Inves Gin Obst, 24, 144-150.

[27] Caruso, S., Iraci, S.M., Agnello, C., Romano, M., Lo, P.L. et al. (2011) Conventional versus extended-cycle oral contraceptives on the Quality of sexual life: Comparison between two regimens containing $3 \mathrm{mg}$ Drospirenone and 20 microg Ethinyl estardiol. Journal of Sexual Medicine, 16, 1743-1761.

[28] Oddens, B.J. (1999) Women's satisfaction with birth control: A population survey of physical and psychological effects of oral contraceptives, intrauterine devices, condoms, natural family planning and sterilization among 1466 women. Contraception, 59, 277-286. doi:10.1016/S0010-7824(99)00034-7

[29] Byne, W. and Parsons, B. (1993) Human sexual orientation. The biologic theories reappraised. Archives of $\mathrm{Ge}$ neral Psychiatry, 50, 228-239.

[30] Lachowsky, M. (1996) What did hormonal contraception change for women. Contracept Fertil Sex, 24, 816-818.

[31] McCoy, N.L. (1996) Oral contraceptives and sexuality in university women. Archives of Sexual Behavior, 1, 73-90. doi:10.1007/BF02437907 